\title{
Hakkari Illinde Görülen Kanser Türlerinin ve Prevalanslarının Değerlendirilmesi
}

\author{
Yusuf Karakaş®
}

Acıbadem Bodrum Hastanesi, Medikal Onkoloji, Muğla, Türkiye

Yusuf Karakaş, Uzm. Dr.

Illetişim:

Uzm. Dr. Yusuf Karakaş

Acıbadem Bodrum Hastanesi, Medikal Onkoloji,

Muğla, Türkiye

Tel: +902523115183

E-Posta:dryusufkarakas@yahoo.com
ÖZET

Amaç: Hakkari ilinde kanser prevalansını belirlemek

Gereç ve Yöntem: Mayıs 2017 - Aralık 2018 arasında Hakkari'de kanser tanısıyla sağlık kuruluşlarına başvuran erişkin hastalar değerlendirildi. Demografik özellikleri ve tanıları belirlendi.

Bulgular: Kanser tanısıyla başvuran 631 hastanın 344 (\%54.5)'i kadın, 287 (\%45.5)'i erkekti. Kadınlarda ilk beş kanser türü sırasıyla; meme, diferansiye tiroid, kolorektal, özofagus ve mide kanseri, erkeklerde ise; mide, akciğer, prostat, kolorektal, ve özofagus kanseri olarak belirlendi.

Sonuçlar: Hakkari ilinde mide ve özofagus kanserleri her iki cins içinde, sık görülen kanser türleri arasında yer almaktadır.

Anahtar sözcükler: Hakkari, Mide kanseri, Özofagus kanseri

TIEVALUATION OF CANCER TYPES AND PREVALENCE IN THE PROVINCE OF HAKKARI, TURKEY

\section{ABSTRACT}

Aim: To determine the prevalence of cancer in the province of Hakkari, Turkey.

Methods: All adult patients diagnosed with cancer who applied to a health care provider in Hakkari between May 2017 and December 2018 were evaluated. Demographic features and types of cancer were determined.

Results: Of the 621 patients diagnosed with cancer, 344 (54.5\%) were female, and 287 (45.5\%) were male. The five most common types of cancer in female patients were; breast cancer, differentiated thyroid cancer, colorectal cancer, esophagus cancer, gastric cancer. In male patients; gastric cancer, lung cancer, prostate cancer, colorectal cancer, esophagus cancer, respectively.

Conclusion: Gastric and esophagus cancer are among the types of cancer with the highest prevalence in the province of Hakkari.

Keywords: Hakkari, Gastric cancer, Esophagus cancer.

7 anser insidansı ve mortalitesi dünyada her geçen gün artmaktadır. Bu artışın sebepleri oldukça karmaşık ve birçok etkenle ilişkilidir. Ortalama yaşam süresinin uzaması, yaşlı nüfusun oransal artması, çevresel faktörlere daha fazla maruziyet, etkin tedavilerle bakteriyel, viral salgınlar, koroner arter hastalığı ve inme gibi hastalıklara bağlı ölümlerin azalması, bu artışın başlıca nedenleri olarak sayılabilir (1). Malign tümörlerin görülme sıklığı bölgesel farklılıklar gösterebilmektedir. Çevre koşulları, bölgenin sanayileşme oranı, halkın sosyoekonomik düzeyi, beslenme 
alışkanlıkları, bazı enfeksiyöz ajanların sıklığı ve genetik özellikler bu farklılığı oluşturan başlıca etkenlerdir (2-4). Mide kanseri dünyada en sık rastlanan 5 . kanser türü iken kansere bağlı ölümlerde 3 . sıradadır ve 5 yıllık sağ kalım \%30'dan daha azdır $(1,5)$. Benzer şekilde özofagus kanseri de en sık görülen 7. kanser türü iken kansere bağlı ölümlerde 6. sıradadır ve her iki kanser türü de mortalitesi en yüksek olan kanser türlerinden kabul edilmektedir (1). Özellikle Türkiye'nin Doğu Anadolu bölgesinde mide ve özefagus kanseri gibi üst gastrointestinal bölge kanserlerinin, diğer kanserlere oranla çok daha fazla morbidite ve mortalitiden sorumlu olduğunu gösteren çalışmalar bulunmaktadır $(6,7)$. Doğu Anadolu bölgesinde Ağrı ve Erzurum illerinde yapılan çalışmalarda da mide ve özofagus kanserlerinin daha sık rastlandığı bildirilmiş $(8,9)$. Hakkari bölgesinde sağlık hizmeti verirken de mide, özofagus kanserlerin diğer bölgelere oranla daha fazla rastlandığı tecrübe edilmiştir. Bu çalışma ile daha önce hiç belirlenmemiş olan Türkiye'nin güneydoğusundaki Hakkari bölgesinin kanser türlerinin prevalansını belirlemek, Türkiye ve dünya insidanslarıyla kıyaslamak ve olası bölgeye özgü endemik kanser türlerinin tespit edilmesi halinde kanser erken tarama programları oluşturmak ve halkın farkındalığını arttırmak hedeflenmiştir.

\section{Gereç ve yöntem}

Hakkari ilinde kanser tanısıyla Mayıs 2017 ile Aralık 2018 tarihleri arasında sağlık kuruluşlarına (Hakkari Devlet Hastanesi ve İlçe Devlet Hastaneleri) başvuran erişkin hastalar değerlendirmeye alındı. Mayıs 2017- Aralık 2018 tarihlerinde poliklinik ve yatakı tedavi verilen hastaların tanıları araştıııldı. Bu süre zarfında yeni kanser tanısı almış veya kanser tanısıyla takip edilen hastalar tespit edildi. Hastaların dosyaları incelenerek demografik özellikleri ve kanser türleri kaydedildi. Aynı hastanın belirlenen tarihler arasında Hakkari ilinde başka sağlık kuruluşlarına başvurmasıyla oluşan mükerrer kayıtlar tespit edilerek çalışmaya alınmadı. Elde edilen verilerle, belirli bir nüfusta, belirli bir zaman dilimi içerisinde, belirli hastalıklara sahip olguların oranı olan, prevalans belirlendi. Çalışma verileri SPSS (versiyon 21.0, Chicago, IL, USA)programına kaydedilerek analizleri yapıldı. Tanımlayıcı istatistiklerden, kategorik değişken için Ki-kare testi, non-kategorik değişkenler için ise Student's t-testi kullanıldı.

\section{Bulgular}

Mayıs 2017 ile Aralık 2018 tarihleri arasında Hakkari ilinde sağlık kuruluşlarına kanser tanısıyla başvuran 716 erişkin hasta tespit edildi. Bu hastalardan $85^{\prime} \mathrm{i}$ mükerrer, farklı sağlık kuruluşlarına başvuran aynı hasta olduğu belirlenerek incelemeye dahil edilmedi. Toplamda Hakkari bölgesinde belirlenen zaman dilimi içerisinde 631 kanser tanılı hasta olduğu görüldü. Bu hastaların 344'ü (\%54.5) kadın, 287'si (\%45.5) erkekti. Kadınlarda en sık görülen ilk 5 kanser türü 66 (\%19.1) meme kanseri, 46 (\%13.7) diferansiye tiroid, 40 (\%11.6) kolorektal, 32 (\%9.3) özofagus, 26 (\%7.5) mide kanserleriydi (Tablo 1). Erkeklerde en sık görülen kanser türleri ise 47 (\%16.3) mide kanseri, 36 (\%12.5) akciğer kanseri, 34 (\%11.8) prostat, 31 (\%10.8) kolorektal ve 26 (\%9) özofagus kanseri olarak belirlendi (Tablo 2). Erkek ve kadınlardaki kanser prevalansları ortalama görülme yaşları ve aralığı Tablo 1 ve 2 de özetlenmiştir.

Tablo 1. Hakkari bölgesi erişkin kadınlarda en sık görülen kanserlerin grup içinde yüzde dağılımı ve yaş aralığı

\begin{tabular}{lcc} 
Kanser türü & $\begin{array}{c}\text { Hasta Sayısı ve } \\
\text { Yüzdesi }\end{array}$ & $\begin{array}{c}\text { Ortalama görülme yaşı } \\
\text { (median), yaş aralığı (range), yıl }\end{array}$ \\
\hline Meme & $66(\% 19.1)$ & $48(28-94)$ \\
Tiroid (Diferansiye) & $46(\% 13.7)$ & $38(31-54)$ \\
Kolorektal & $40(\% 11.6)$ & $59(32-78)$ \\
Özofagus & $32(\% 9.3)$ & $51(39-68)$ \\
Mide & $26(\% 7.5)$ & $59(45-76)$ \\
Baş/Boyun & $18(\% 5.2)$ & $55(48-79)$ \\
Akciğer & $17(\% 4.9)$ & $61(51-78)$ \\
Beyin & $14(\% 4)$ & $53(41-67)$ \\
Over & $13(\% 3.8)$ & $63(51-76)$ \\
Böbrek & $10(\% 3)$ & $64(44-81)$ \\
Mesane & $10(\% 3)$ & $68(56-75)$ \\
Sarkom & $10(\% 3)$ & $57(44-78)$
\end{tabular}

Tablo 2. Hakkari bölgesi erişkin erkeklerde en sık görülen kanserlerin grup içinde yüzde dağııımı ve yaş aralığı

\begin{tabular}{lcc} 
Kanser türü & $\begin{array}{c}\text { Hasta Sayısı ve } \\
\text { Yüzdesi }\end{array}$ & $\begin{array}{c}\text { Ortalama görülme yaşı, } \\
\text { yaş aralığı (range), yıl }\end{array}$ \\
\hline Mide & $47(\% 16.3)$ & $57(39-80)$ \\
Akciğer & $36(\% 12.5)$ & $64(44-72)$ \\
Prostat & $34(\% 11.8)$ & $62(43-81)$ \\
Kolorektal & $31(\% 10.8)$ & $59(36-76)$ \\
Özofagus & $26(\% 9)$ & $55(33-71)$ \\
Mesane & $20(\% 7)$ & $60(41-78)$ \\
Testis & $19(\% 6.6)$ & $28(19-44)$ \\
Baş/Boyun & $11(\% 3.8)$ & $61(52-76)$ \\
Pankreas & $10(\% 3.5)$ & $63(44-80)$ \\
Beyin & $10(\% 3.5)$ & $56(36-82)$ \\
Non-Hodgkin Lenfoma & $9(\% 3.1)$ & $65(51-78)$ \\
Böbrek & $9(\% 3.1)$ & $61(48-84)$
\end{tabular}

Kanser tanısıyla takip edilen 631 hastanın 574 (\%91)'i Hakkari Devlet Hastanesine başvurmuş hastalardı. Geriye kalan 57 hasta, Hakkari Illçelerindeki Devlet Hastanelerine başka nedenlerle başvurmuş kanser hastalarıydı. Hastalardan sadece 22 (\%3.5)'inin doğum yeri veya yaşadığı yer Hakkari Bölgesi dışındaydı. Hastaların büyük çoğunluğu (609 hasta-\%96.5) Hakkari'de doğmuş ve bu bölgede yaşamış olduğu görüldü. 


\section{Tartışma}

Kanser türleri ve görülme sıklıkları bölgesel farklılıklar gösterebilmektedir. Kanser gelişiminde birçok çevresel etken, beslenme alışkanlıkları ve genetik özelliklerin rol aldığı düşünüldüğünde, bu beklenen bir sonuçtur $(1,10)$. Erkeklerde ve kadınlarda en sık görülen kanser türlerinin dağılımı Türkiye ve dünya verileriyle kıyaslanarak Tablo 3 ve 4'de sunulmuştur. Daha önce birçok çalışma, mide ve özofagus kanserlerinin bölgesel olarak sıklığının en çok değişen kanser türleri olduğu gösterilmiştir $(1,10,11)$. Dünyada üst gastrointestinal sistem kanser kuşağı olarak tanımlanan, doğuda Japonya, Çin, Kore, Orta Asya'da Özbekistan, Türkmenistan ve yakın doğumuzda Kafkasya, İran ve Anadolu'nun doğusunu içine alan bölgede mide, özofagus kanserleri önemli bir mortalite ve morbidite sebebidir ve dünyadaki en yüksek mide, özofagus kanser insidansının olduğu yerlerdir $(1,12)$. Bu çalışmamızda Hakkari'de erkeklerde en sık görülen kanserin mide kanseri olduğu, dünya insidansından yaklaşık 2 kat, Türkiye insidansından da yaklaşık 3 kat daha fazla görüldüğü tespit edildi. Görülme sıklığı ise çalışmamızla benzer şekilde erkeklerde, kadınlara göre 2 kat daha fazlaydı $(1,13)$. Mide kanserinin bölgesel insidans farklılı̆ının genetik alt yapıdan etkilendiğini gösteren birçok göçmen çalışması vardır. Örneğin mide kanseri insidansı yüksek olan Japonya'dan Hawai'ye göç edenlerin 1. kuşağında, mide kanseri insidansının, Japonya'dakinden daha az olduğu ve 2 . kuşak Hawai'de yaşayan Japonlarda insidansın Japonya'dakine göre daha da azaldığı ancak halen yerli Hawai halkından daha fazla olduğu gösterilmiştir (14-17). Hakkari ili göç almayan bir ilimizdir ve hastaların \%96.5'inin doğum yeri ve yaşadığı yerin Hakkari olduğu görülmüştür. Bu durum Hakkari'de genetik risk faktörlerinin varlığının kanıtı olarak sayılabilir. Mide kanserleri bilinen başıca risk faktörleri; ileri yaş, erkek cinsiyet, genetik özellikler, yoğun sigara ve alkol tüketimi, rasyasyon maruziyeti, aile hikayesi, Helikobakter pilori enfeksiyonu, düşük sosyo-ekonomik düzey, yoğun salamura ve tütsülenmiş yiyeceklerin tüketilmesi, lokal travmaya neden olacak kadar sıcak içecekler, diyette meyve ve sebzelerin az olması, obesite ve gastro-ösefageal reflü olarak sıralanabilir $(5,11,12,18-23)$. Hakkari ilimiz ne yazık ki sosyo-ekonomik gelişmiş derecelendirmesinde 5 . kategoride ve ülkemizin en düşük gelişmişlik seviyesindeki illerimizden birisidir. Bölgenin çetin coğrafik ve iklim özellikleri nedeniyle gıdaların uzun süre saklananabilmesi için salamura edilmekte ve meyve ve sebzenin günlük beslenmede yerinin az olduğu gözlenmiştir. Bununla birlikte tüm dünyada son 50 yılda mide kanseri insidansı ve mortalitesinin azaldığı görülmüştür. Bunun nedeni olarak Helikobakter pilori enfeksiyonunun antibiyotik kullanımıyla azaltılması, taze meyve ve sebzeye daha rahat ulaşılabilmesi, salamura veya tuzluyarak gıdaların saklanması yerine buzdolaplarının çok daha yaygın kullanılması, yoğun sigara ve alkol alımının azalması ile açıklanmaktadır (10, 24-26).

Mide kanserinde olduğu gibi özofagus kanserinde de bölgelere göre insidansların çok değişken olması dikkat çekicidir $(27,28)$. Özofagus kanseri de genelde erkeklerde, kadınlara oranla 3-4 kat daha sık görülür ve özofagus kanserinin etiyolojisi histolojik alt tipine göre farklılık göstermektedir. Skuamoz hücreli tip sıklıkla mide- özofagus kanser kuşağı olarak bilinen bölgelerde daha sık olmak üzere, yoğun sigara ve alkol alımı, meyve-sebzelerin az tüketilmesi, lokal travmaya neden olacak sıcak içecekler içilmesiyle ilişkilendirilmektedir (29-32). Adenokanser tipi ise genelde özofagus kanserlerinin nadir görüldüğü bölgelerde, obesite ve gastrik reflü nedeniyle oluşan Barrett

Tablo 3. Tüm yaş gruplarında, erkeklerde en sık görülen kanser türlerinin yüzde dağılımları

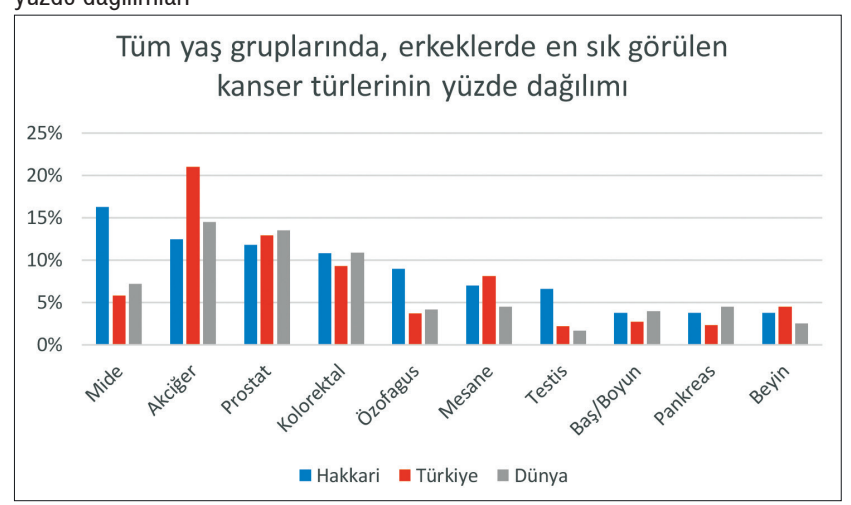

Tablo 4. Tüm yaş gruplarında, kadınlarda en sık görülen kanser türlerinin yüzde dağılımları

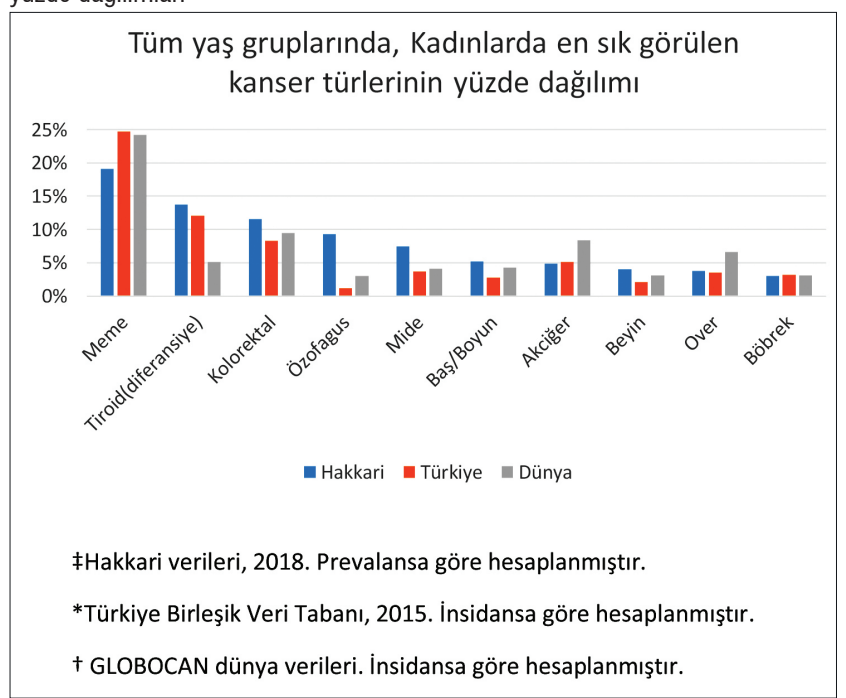


özofagusuna bağlı oluşmaktadır. Özofagus kanseri de mide kanseri gibi, sigara ve alkolden kaçınıp, bol lifli besinlerle beslenmek gibi sağlıklı yaşam şekliyle riski azaltılabilir. Ancak görülme sıklığı fazla olan endemik bölgelerde mide ve özofagus kanseri halen ciddi sorun oluşturmaya devam etmektedir (33).

Endoskopi mide ve özofagus kanserlerinde tanıda ve prekanseröz lezyonların takibinde altın standart uygulamadır $(5,34)$. Yapılan endoskopiyle sadece kanser tanısı tespiti değil prekanseröz lezyonların belirlenmesi de çok önemlidir. Prekanseröz lezyonların 10 yıl takip edildiği bir çalışmada hafif-orta ve yüksek displazili lezyonların sırasıyla \%4 ve \%33 oranında mide kanserine dönüştüğü gözlenmiştir (35). Ancak mide kanserine erken tanı koymak için endoskopik tarama yapılması oldukça maliyetlidir bu nedenle mide-özefagus kanser insidansı düşük bir çok gelişmiş ülkede endoskopik tarama maliyet etkin bulunmadığından rutin pratiğe geçmemiştir $(1,11)$. Mide-özofagus kanserinde tarama ancak yüksek insidansa sahip bölgelerde önerilebilir $(26,36,37)$. Bu bağlamda mide kanseri insidansı yüksek ülkelerde yapılan tarama programlarıyla \%30-\%60 oranında mide kanserine bağlı ölümlerin azaltıldığı gösterilmiş̧ir (38-40). Ayrıca Avrupa ülkelerinde mide kanserinde 5 yıllık sağ kalım \%10-30 arasındayken (41), bu oran Japonya'da \%90'a kadar çıkmaktadır. Japonya'da sık görülen mide kanserindeki bu başarı toplumsal farkındalık ile endoskopik erken tanı ve ardından erken rezeksiyon ile gerçekleşmektedir (26). Japonya'da 50 yaşından sonra 2 yıl aralıklarla endoskopi ile tarama programı

\section{Kaynaklar}

1. Bray F, Ferlay J, Soerjomataram I, Siegel RL, Torre LA, Jemal A. Global cancer statistics 2018: GLOBOCAN estimates of incidence and mortality worldwide for 36 cancers in 185 countries. CA: Cancer J Clin 2018; 68: 394-424. [CrossRef]

2. Nazlıgül Y, Sabuncu T, Dalmaz M, Cebeci B, Bitiren M, Kösecik M. Şanlıurfa'da 1990-1994 Yılları Arasında Kanser Vakaları. Van Tıp Dergisi 1997; 4: 198-200.

3. Youn Nam S, Park BJ, Nam JH, Ryu KH, Kook M-C, Kim J, et al. Association of current Helicobacter pylori infection and metabolic factors with gastric cancer in 35,519 subjects: A cross-sectional study. United European gastroenterology journal 2019; 7: 287-96. [CrossRef]

4. Yalcin S. Gastric cancer in Turkey - a bridge between West and East. Gastrointestinal cancer research: GCR 2009; 3: 29.

5. Rugge M, Genta RM, Di Mario F, El-Omar EM, El-Serag HB, Fassan M, et al. Gastric cancer as preventable disease. Clinical Gastroenterology and Hepatology 2017; 15: 1833-43. [CrossRef]

6. Turkdogan M, Akman N, Tuncer I, Dilek F, Akman E, Memik F, et al. The high prevalence of esophageal and gastric cancers in Eastern Turkey. Médecine Biologie Environnement 1998; 26: 79-84. uygulanmaktadır (42). Çalışmamızın sınırlılıkları ise öncelikle retrospektif, veri tarama şeklinde dizayn edilmiş olmasıdır. Bunun yanında dünya ve Türkiye verileri hastalıkların indisansılarıdır, yani belirli bir nüfusta, belirli bir zaman dilimi içerisinde belirli bir hastalığa ait yeni olguların sayısını ifade eder. Oysa bizim çalışmamız belirli zaman dilimi içerisindeki hastalıklara sahip olguların oranı olan prevalans değeridir. Diferansiye tiroid ,meme, kolon ve prostat kanserlerinin uzun sağ kalım değerlerine kıyasla mide ve özofagus kanserlerinin mortalitesinin yüksekliği düşünüldüğünde, Hakkari ilindeki mide, özofagus kanserinin görülme insidansının daha da fazla olduğu düşünülebilir. Ayrıca çalışmamızda kanser hastalarının Helikobakter pilori enfeksiyonu ile ilişkisi, tümörlerin histolojik alt tipleri, obesite durumlarına ait veri bulunmamaktadır.

Ülkemiz için mide ve özofagus kanserlerinde bölgesel insidans farklılıkları, sosyo-ekonomik faktörler, genetik alt yapı göz önünde bulundurularak sağlık yöneticileri, sağlık yöneticileri, onkoloji, gastroenteroloji, genel cerrahi ve patoloji uzmanlarınca sağlık politikaları oluşturulmalıdır $(5,43)$.

\section{Sonuç}

Ülkemizin güneydoğusunda bulunan ve mide-özofagus kanseri kuşağında yer alan Hakkari bölgesinde, mide ve özofagus kanserlerinin en sık görülen kanser türlerinden biri olduğu ve Türkiye ve dünya insidansından daha sık rastlandığı tespit edilmiştir.

7. Onuk M, Öztopuz A, Polat G. Risk factors of esophageal cancer in Eastern Turkey. Radioter Oncol Med 2000; 2: 28-9.

8. Caglar E, Balaban K, Atasoy D, Caglar AS, Akay A. The incidences of upper gastrointestinal and colorectal malignancies in Ağrı city of eastern Anatolia. Cumhuriyet Tıp Dergisi; 2019;41:537-43. [CrossRef]

9. Eroğlu A, Aydin Y, Altuntaş B, Gündoğdu B, Yılmaz Ö. The increasing incidence of esophageal squamous cell carcinoma in women in Turkey. Turk J Med Sci 2016;46:1443-8. [CrossRef]

10. Aguilar I, Compés L, Feja C, Rabanaque MJ, Martos C. Gastric cancer incidence and geographical variations: the influence of gender and rural and socioeconomic factors, Zaragoza (Spain). Gastric Cancer 2013; 16: 245-53. [CrossRef]

11. In $H$, Langdon-Embry $M$, Gordon L, Schechter CB, Wylie-Rosett $J$, Castle $P E$, et al. Can a gastric cancer risk survey identify highrisk patients for endoscopic screening? A pilot study. J Surg Res. 2018;227: 246-56. [CrossRef]

12. Turkdogan M, Testereci H, Akman N, Kahraman T, Kara K, Tuncer I, et al. Dietary nitrate and nitrite levels in an endemic upper gastrointestinal (esophageal and gastric) cancer region of Turkey. Turk J Gastroenterol 2003; 14: 50-3.

13. Bosman FT, Carneiro F, Hruban RH, Theise ND. WHO classification of tumours of the digestive system. World Health Organization; 2010. 
14. Kolonel LN, Hankin JH, Nomura AM. Multiethnic studies of diet, nutrition and cancer in Hawaii. Diet, nutrition, and cancer 1986:29-40.

15. Lunet N, Valbuena C, Vieira AL, Lopes C, Lopes C, David L, et al. Fruit and vegetable consumption and gastric cancer by location and histological type: case-control and meta-analysis. European Journal of Cancer Prevention 2007; 16: 312-27. [CrossRef]

16. Gomez SL, Shariff-Marco $S$, DeRouen $M$, Keegan $T H$, Yen $I H$, Mujahid $M$, et al. The impact of neighborhood social and built environment factors across the cancer continuum: current research, methodological considerations, and future directions. Cancer 2015;121: 2314-30. [CrossRef]

17. Kim Y, Park J, Nam B-H, Ki M. Stomach cancer incidence rates among Americans, Asian Americans and Native Asians from 1988 to 2011. Epidemiol health 2015; 37:e2015006. [CrossRef]

18. Fock KM. Review article: the epidemiology and prevention of gastric cancer. Aliment pharmacol ther. 2014; 40: 250-60. [CrossRef]

19. Karimi P, Islami F, Anandasabapathy S, Freedman ND, Kamangar F. Gastric cancer: descriptive epidemiology, risk factors, screening, and prevention. Cancer Epidemiol Biomarkers Prev 2014;23: 700-13. [CrossRef]

20. Lui FH, Tuan B, Swenson SL, Wong RJ. Ethnic disparities in gastric cancer incidence and survival in the USA: an updated analysis of 1992-2009 SEER data. Digestive diseases and sciences 2014;59:302734. [CrossRef]

21. Wu X, Chen VW, Andrews PA, Ruiz B, Correa P. Incidence of esophageal and gastric cancers among Hispanics, non-Hispanic whites and non-Hispanic blacks in the United States: subsite and histology differences. Cancer causes \& control 2007;18: 585-93. [CrossRef]

22. González CA, Agudo A. Carcinogenesis, prevention and early detection of gastric cancer: where we are and where we should go. International journal of cancer 2012; 130: 745-53. [CrossRef]

23. Cancer IAfRo. Personal habits and indoor combustions. IARC monographs on the evaluation of carcinogenic risks to humans 2012; 100: 319-31.

24. Parkin DM. The global health burden of infection-associated cancers in the year 2002. Int j cancer 2006; 118: 3030-44. [CrossRef]

25. Bertuccio P, Chatenoud L, Levi F, Praud D, Ferlay J, Negri E, et al. Recent patterns in gastric cancer: a global overview. Int $\mathrm{j}$ cancer 2009; 125: 666-73. [CrossRef]

26. Sitarz R, Skierucha M, Mielko J, Offerhaus GJA, Maciejewski R, Polkowski WP. Gastric cancer: epidemiology, prevention, classification, and treatment. Cancer manag res. 2018; 10: 239-48. [CrossRef]

27. Thursz M, Fontanet A. HCV transmission in industrialized countries and resource-constrained areas. Nat Rev Gastroenterol hepatol. 2014; 11: 28-35. [CrossRef]

28. Huang $X$, Hong $C$, Peng $Y$, Yang $S$, Huang L, Liu C, et al. The Diagnostic Value Of Serum IGFBP7 In Patients With Esophageal Squamous Cell Carcinoma. J Cancer 2019;10:2687-93. [CrossRef]
29. Islami F, Boffetta P, Ren JS, Pedoeim L, Khatib D, Kamangar F. Hightemperature beverages and foods and esophageal cancer risk- $A$ systematic review. Int J Cancer 2009;125:491-524. [CrossRef]

30. Islami F, Pourshams A, Nasrollahzadeh D, Kamangar F, Fahimi S, Shakeri R, et al. Tea drinking habits and oesophageal cancer in a high risk area in northern Iran: population based case-control study. BMJ 2009; 338: b929. [CrossRef]

31. Rasool S, Ganai B, Syed Sameer S, Masood A. Esophageal cancer: associated factors with special reference to the Kashmir Valley. Tumori Journal 2012; 98: 191-203. [CrossRef]

32. Wu M, Liu AM, Kampman $E$, Zhang ZF, van't Veer $P$, Wu $D L$, et al. Green tea drinking, high tea temperature and esophageal cancer in high-and low-risk areas of Jiangsu Province, China: A populationbased case-control study. Int J Cancer 2009;124:1907-13. [CrossRef]

33. Torre LA, Siegel RL, Ward EM, Jemal A. Global cancer incidence and mortality rates and trends-an update. Cancer Epidemiol Biomarkers Prev 2016; 25: 16-27. [CrossRef]

34. Hayden JD, Cawkwell L, Sue-Ling H, Johnston D, Dixon MF, Quirke P, et al. Assessment of microsatellite alterations in young patients with gastric adenocarcinoma. Cancer 1997; 79: 684-7. [CrossRef]

35. De Vries AC, Van Grieken NC, Looman CW, Casparie MK, de Vries E, Meijer GA, et al. Gastric cancer risk in patients with premalignant gastric lesions: a nationwide cohort study in the Netherlands. Gastroenterology 2008; 134: 945-52. [CrossRef]

36. Leung WK, Wu M-s, Kakugawa Y, Kim JJ, Yeoh K-g, Goh KL, et al. Screening for gastric cancer in Asia: current evidence and practice. Lancet Oncol 2008; 9: 279-87. [CrossRef]

37. Dicken BJ, Bigam DL, Cass C, Mackey JR, Joy AA, Hamilton SM. Gastric adenocarcinoma: review and considerations for future directions. Ann surg 2005; 241: 27-39. [CrossRef]

38. Oshima A, Hirata N, Ubukata T, Umeda K, Fujimoto I. Evaluation of a mass screening program for stomach cancer with a case-control study design. Int J Cancer 1986; 38: 829-33. [CrossRef]

39. Hamashima C, Ogoshi K, Okamoto M, Shabana M, Kishimoto T, Fukao A. A community-based, case-control study evaluating mortality reduction from gastric cancer by endoscopic screening in Japan. PLoS One 2013; 8: e79088. [CrossRef]

40. Lin S, Qi W, Han K, Gan Z, Yao Y, Miu D. Prognostic value of SOX2 in digestive tumors: a meta-analysis. Hepatogastroenterology. 2014;61:1274-8.

41. Parkin DM, Bray F, Ferlay J, Pisani P. Global cancer statistics, 2002. CA: Cancer J Clin 2005; 55: 74-108. [CrossRef]

42. Hamashima C, Group SR, Guidelines GDGfGCS. Update version of the Japanese guidelines for gastric cancer screening. Jpn J Clin Oncol 2018; 48: 673-83. [CrossRef]

43. Arnold M, Soerjomataram I, Ferlay J, Forman D. Global incidence of oesophageal cancer by histological subtype in 2012. Gut 2015;64:381-7. [CrossRef] 